\title{
Cultura lúdica na era digital: alguns efeitos no comportamento infantojuvenil \\ Tânia Ramos Fortuna
}

\section{Resumo}

O fato de que atualmente a maioria dos indivíduos entra em contato com o mundo pela tela do computador ou da televisão determina formas de cognição diversas daquelas que por várias décadas influenciaram nosso modo de pensar, o que incide, obviamente, sobre o comportamento infantojuvenil. Uma breve revisão de algumas abordagens teóricas que identificam nas novas mídias prejuízos e riscos ao desenvolvimento infantojuvenil é apresentada, e, em seguida, analisa-se o que alguns pesquisadores contemporâneos dizem acerca dos benefícios e das vantagens da era digital para o comportamento humano, especialmente o das crianças. Muitas das preocupações que cercam a discussão sobre o comportamento lúdico na contemporaneidade não são novas, não obstante a recente presença da tecnologia digital na sociedade. Conclui com uma reflexão sobre o papel do adulto diante das crianças e dos jovens em relação à cultura lúdica na era digital.

Palavras-chave: cultura lúdica; brincar; era digital; mídias eletrônicas; comportamento infantojuvenil. 


\section{Abstract \\ Playing culture in the digital era: some impacts on youth behavior}

The fact that recently most individuals connect with the world through the screen of a computer or television establishes different types of cognition from those that over many decades influenced our thinking pattern, which obviously affects youth behavior. It is presented a brief review of some theoretical approaches that understand the novel media as a source of risks and liabilities to youth development, and, subsequently, there is an analysis on the findings of some contemporary researchers on the benefits and advantages of the digital era for human behavior, especially that of children. Many of the concerns about the discussion on contemporary playing behavior are not new, notwithstanding the recent emergence of digital technology in society. It concludes with some thoughts on the role played by the adult vis-à-vis the youth with regard to the playing culture in the digital era.

Keywords: playing culture; play; digital era; electronic media; youth behavior.

\section{Resumen \\ Cultura lúdica en la era digital: algunos efectos en el comportamiento infantojuvenil}

El hecho de que actualmente la mayoría de los individuos entra en contacto con el mundo por la pantalla de la computadora o de la televisión determina formas de cognición diversas de aquellas que por varias décadas influenciaron nuestro modo de pensar, lo que incide, obviamente, sobre el comportamiento infantojuvenil. Una breve revisión de algunos enfoques teóricos que identifican en los nuevos medios perjuicios y riesgos al desarrollo infantojuvenil es presentada y, a continuación, se analiza lo que algunos investigadores contemporáneos dicen acerca de los beneficios y de las ventajas de la era digital para el comportamiento humano, especialmente el de los niños. Muchas de las preocupaciones que rodean la discusión sobre el comportamiento lúdico en la contemporaneidad no son nuevas, a pesar de la reciente presencia de la tecnología digital en la sociedad. Concluye con una reflexión sobre el papel del adulto ante los niños y los jóvenes en relación a la cultura lúdica en la era digital.

Palabras clave: cultura lúdica; jugar; era digital; medios electrónicos; comportamiento infantojuvenil. 


\section{Introdução}

Certamente o fato de que, atualmente, a maioria dos indivíduos toma contato com o mundo pelas telas do computador ou da televisão determina formas de cognição diversas daquelas que, por várias décadas, influenciaram nosso modo de pensar. Estudos demonstram que até mesmo a maneira de ler mudou (veja-se, por exemplo, Carr, 2010), assim como se transformou o modo de interação com os outros. Aí estão o hipertexto e a navegação na internet para demonstrar que as formas de leitura e sua relação com a escrita abrem lugar, hoje, a uma posição mais dinâmica por parte do leitor, que se torna, no mais das vezes, simultaneamente, um escritor. Enquanto isso, os contatos reais prolongados com as pessoas experimentam uma acentuada mudança, tanto em relação ao tempo neles investido quanto, principalmente, ao seu conteúdo: nas grandes cidades até se pode encontrar mais pessoas em um dia do que em uma vida inteira há três décadas, por exemplo, mas tais encontros são, majoritariamente, superficiais e rápidos.

Essa situação, tão característica da contemporaneidade e particularmente beneficiada pela globalização, com a difusão em massa das novas tecnologias e seus conteúdos, incide, é claro, sobre o comportamento, levando aos questionamentos:

- Quais seus efeitos na cultura lúdica e na constituição do aparelho psíquico de crianças e jovens?

- Será que a capacidade de imaginar está sendo afetada? De que modo?

- E quanto à atividade psíquica, qual a influência das novas mídias no funcionamento mental, especialmente dos indivíduos jovens que se encontram nas etapas iniciais de desenvolvimento?

- Qual o impacto dessas mídias na cultura lúdica, isto é, nos modos de brincar, no valor atribuído à brincadeira e à diversão e no próprio repertório de jogos e brincadeiras das crianças de hoje?

- Estarão algumas brincadeiras e a própria capacidade de brincar correndo risco de extinção?

O objetivo do presente texto é propor possíveis respostas a essas questões.

\section{Algumas críticas às novas tecnologias quanto ao impacto no comportamento infantojuvenil}

São numerosos e alarmantes os efeitos da interação com as novas tecnologias sobre o comportamento infantojuvenil, identificados por pesquisadores na área, e deles é possível deduzir um impacto marcante na cultura lúdica.

Muitos psiquiatras e psicólogos (Levisky, 1998; Colonnese, 1998) denunciam o prejuízo causado pelos meios eletrônicos à capacidade de escolha do indivíduo, em virtude do controle do espaço interno exercido pelos estímulos externos, que direcionariam as atividades psíquicas conscientes e inconscientes. A capacidade de 
criar, pensar e analisar criticamente estaria sendo afetada, tanto quanto aqueles desejos que o processo civilizatório se esforçou em reprimir e que sofreriam uma espécie de dessublimação.

Assim, do ponto de vista psíquico, alguns dos produtos desses meios eletrônicos - como determinados programas televisivos e jogos -, graças à produção de um estado de tensão constante, não deixariam tempo para a elaboração interior de seu conteúdo.

Além do mais, propiciariam o estabelecimento de um estado mental regressivo, no qual as emoções recalcadas poderiam encontrar vias de vazão, favorecendo o processo primário, em que predominam mecanismos de identificação projetiva; as mensagens seriam, desse modo, mais facilmente induzidas, com as fantasias dirigidas. Note-se que os estados primitivos da mente são especialmente propícios à passagem ao ato, aumentando as chances de comportamento violento. Acreditase, assim, que esses produtos seriam indutores de violência, uma vez que aumentariam a probabilidade de as crianças se envolverem em atos manifestos de agressão (Singer; Singer, 2007; Strasburger, 1999).

Considerando especialmente o brincar, soma-se a esses possíveis efeitos dos meios eletrônicos o fato de que eles imporiam seu próprio ritmo lúdico, sem levar em conta a capacidade incipiente de crianças e jovens exercerem autocontrole sobre suas atividades lúdicas. Seu alto poder de imersão facilitaria a emergência do comportamento compulsivo, criando, desse modo, condições favoráveis à instalação da adicção. Reféns da busca constante de satisfação instalada pelo flow (estado de experiência máxima) e sem experimentar as consequências concretas dos próprios atos no ambiente lúdico virtual, as crianças teriam diminuída a sua capacidade de tolerância à frustração.

Ademais, vários profissionais das áreas de educação e saúde infantojuvenil (Weiss, 2001; Cosenza, 2011) observam que o acesso fácil e sem controle a tais meios levaria à diminuição das horas de sono e de obrigações domésticas e escolares.

Aliás, na disputa pelo tempo e pelo interesse das crianças e dos jovens, a escola estaria em grande desvantagem em relação ao poder das multinacionais do ócio e do comércio digital. Vivendo em ambientes com eletrônicos superestimulantes, os jovens sentir-se-iam entediados na escola, na maior parte das vezes ainda distante do mundo digital, ou, quando muito, com experiências extemporâneas de aprendizagem nesse âmbito (Sancho, 2013).

Não bastassem essas críticas, alguns estudos consideram que os produtos eletrônicos, em especial aqueles beneficiados pelos recursos cada vez mais amplos da tecnologia digital, ao exacerbarem a fantasia e criarem uma confusão propositada entre o que é real e o que é imaginário, dificultariam a distinção entre realidade e faz de conta, podendo levar, até mesmo, à negação da realidade (Singer; Singer, 2007). Outros estudos, inversamente, identificam um "déficit de magia" em muitos desses produtos, cujo hiper-realismo e ausência de oportunidade para a invenção e a criação prejudicariam o desenvolvimento de brincadeiras mais complexas e criativas. Seja como for, todas essas condições determinariam uma assimilação fácil, sem barreiras, nem crítica, a quaisquer conteúdos e mensagens veiculados. A brincadeira, assim colonizada, ficaria completamente à mercê de interesses espúrios. 
Outra questão apontada pelos estudiosos do comportamento humano que criticam as novas mídias (Levisky, 1998; Colonnese, 1998), com implicações para os jogos eletrônicos, quer estejam em consoles (os videogames), máquinas dedicadas, aparelhos de telefonia celular (dos mais simples até os smartphones) e aparelhos portáteis como o Gameboy, quer estejam em computadores PC e portáteis, como os tablets e os PDAs (Personal Digital Assistent ou palmtop), é que as relações de objeto estabelecidas com essas mídias são, predominantemente, do tipo parcial, isto é, prescindem de uma visão integradora daquilo com o que se relacionam. Nessa relação, o objeto não só é tomado isoladamente, como ele mesmo é fragmentado, a fim de cumprir uma função específica, perdendo seu valor de conjunto. Tais relações contribuiriam para dar lugar, posteriormente, a relações inter-humanas dessubjetificantes e, por isso, violentas, nas quais o outro não é concebido como um sujeito inteiro, com vontade própria, qualidades e defeitos, e, sim, "usado" em função daquilo que ele pode satisfazer. Também por isso, acredita-se que a cultura lúdica digital potencializaria a solidão, o isolamento e a abdicação de contatos sociais reais.

Entretanto, não é necessário recorrer a estudos científicos e à opinião dos especialistas para perceber que as condições propícias para contatos sociais reais são cada vez mais raras entre as crianças de hoje, sobretudo nas grandes cidades. Oriundas de famílias com menor número de filhos, distantes dos demais familiares (primos, avós, tios) devido à lógica da vida urbana e das novas configurações familiares, essas crianças têm escassas oportunidades para brincar umas com as outras: a rua, com suas calçadas, parques e praças, é vista como ameaçadora e ir à casa de outra criança é difícil, implicando deslocamentos por vezes onerosos e tempo disponível de adultos que possam levá-la e de outros que se responsabilizem por ela enquanto estiver lá.

Em contrapartida, no tempo que passam na maioria das escolas, o único momento da rotina escolar permitido à brincadeira é o recreio, cujos 15 ou 20 minutos são, também, destinados a merendar, tomar água e ir ao banheiro. Como se pode perceber, a infância contemporânea é, cada vez mais, vivida indoor.

Há quem identifique, inclusive, um "déficit de natureza" na infância atual, dado que as crianças estariam crescentemente sedentárias, sem contato com o ambiente natural e sem oportunidades para praticar atividades ao ar livre.

À criança resta, então, a alternativa de brincar sozinha, dentro de casa. Enquanto algumas crianças brincam na companhia da televisão - pois, como disse uma menina de 7 anos de idade em uma pesquisa sobre o brincar das crianças brasileiras, "é chato brincar sozinha, e com a tevê ligada, ela fica falando" (Carneiro; Dodge, 2007, p. 155) -, outras jogam jogos eletrônicos.

Diante desse panorama sombrio, as indagações se revigoram: afinal, como as diferentes formas de brincar e os brinquedos criados ao longo da História são experimentados pela infância atual? De que maneira essa cultura lúdica, com seu vasto repertório de jogos, brincadeiras e brinquedos, amealhado por séculos, por diversos povos, em diferentes lugares e em condições tão diversas (e, frequentemente, adversas), e que integra o patrimônio cultural da humanidade, será conhecida no futuro? 
Observe-se que a criação, a recriação e a transmissão da cultura lúdica ocorrem por meio de trocas intra e intergeracionais: tanto a invenção quanto a difusão de práticas lúdicas requerem tempo, espaço e parceiros com quem aprender e ensinar a brincar. Fórmulas de escolha, jogos de mãos, brinquedos e as mais diversas brincadeiras e jogos, com seus modos específicos de serem executados, segundo variadas e complexas regras, só ganham existência de uma maneira: brincando. É brincando que as brincadeiras são aprendidas e ensinadas.

Sendo assim, cabe perguntar, de forma mais incisiva: estarão a cultura lúdica tradicional e a própria capacidade de brincar, ante a solidão, o sedentarismo infantil e a cultura lúdica digital, fadadas à extinção?

Para propor uma resposta a essa pergunta e também às indagações anteriores, examinaremos, antes, o que outros tantos estudiosos (Weiss, 2001; Veen; Wrakking, 2011, Palfrey; Gasser, 2011) têm propalado acerca dos benefícios e das vantagens da era digital para o comportamento humano, especialmente o das crianças.

\section{Possíveis benefícios das novas tecnologias para o comportamento humano}

Um dos benefícios diz respeito ao aumento das oportunidades de ampliação das funções cognitivas humanas - memória, imaginação, percepção, raciocínio -, que seriam estimuladas pelos diferentes sentidos postos em jogo na exploração das novas tecnologias, tais como tato, visão, audição e sinestesia. Muitas delas forneceriam ao usuário o controle de uma ampla variedade de fluxos de informação e comunicação e seriam, por isso, especialmente propícias ao desenvolvimento da autonomia e da iniciativa na busca do conhecimento. Aliás, os recursos de mobilidade e a maior autonomia no controle desses meios eletrônicos concorreriam decisivamente para isso, dada a possibilidade cada vez maior de permitirem selecionar a informação de modo eficiente, adequado e imediato, conforme as necessidades de cada um. Disso decorreria uma perda de tolerância em relação aos modos passivos de aprendizagem, com rejeição às formas tradicionais de ensino.

Tais comportamentos, somados à melhoria do processamento das informações, da atenção visual, da coordenação visomotora e da memória operacional, estariam em sintonia com as novas competências cognitivas, em termos de velocidade, capacidade de manipulação de modelos complexos e descoberta de regras não explícitas por meio da exploração autônoma ou induzida. Segundo essa perspectiva, crianças e adolescentes com larga experiência com meios eletrônicos teriam mais possibilidade de êxito no mundo atual, altamente tecnologizado.

Diferentemente dos detratores das novas tecnologias em relação aos seus efeitos deletérios sobre o desenvolvimento e a aprendizagem infantojuvenil, vários estudiosos (McGonigal, 2012; Gularte, 2010; Martinez, 2011; Folque, 2011; Palfrey; Gasser, 2011) enfatizam seu potencial para a ampliação do conhecimento e da cultura, devido aos desafios propostos, o que suscitaria a curiosidade, o interesse e, até, posteriormente, o aumento do pensamento divergente. Eles também defendem que, 
graças às trocas online propiciadas pela internet, muitos dos jogos eletrônicos, antes jogados a sós, instaurariam um tipo de sociabilidade capaz de contrarrestar a tendência à solidão infantil nas grandes cidades. Essa sociabilidade virtual contribuiria para a construção da personalidade, o enfrentamento da timidez e a ampliação dos contatos sociais, além de estimular a aprendizagem coletiva, na qual todos aprendem com todos. No limite, McGonigal (2012) defende que, com os jogos de computador e os videogames, a partir de seu mundo virtual, é possível mudar a própria realidade, como um todo.

Quanto à indução de comportamentos agressivos, estudos como, por exemplo, o de Alves (2005) ponderam que os jogos eletrônicos, em si mesmos, não têm todo esse poder, desempenhando, isto sim, um papel catártico para a agressividade existente em todos nós, ao ressignificarem insatisfações e expressá-las de modo socialmente aceitável e sem consequências para o mundo real. Já a banalização da violência que a alta exposição aos jogos eletrônicos de temática violenta engendraria é contestada com o argumento de que violento é o ato, concreto ou simbólico, que destitui a pessoa de sua condição de sujeito, tratando-a como mero objeto. A dessensibilização à violência proviria justamente da passividade ante as situações violentas. Daí que, nos jogos eletrônicos em que os jogadores assumem uma posição ativa, de enfrentamento a essas situações, longe de habituarem-se a elas, naturalizando-as, desenvolveriam uma posição crítica a respeito, sobretudo quando a interação com esses conteúdos fosse mediada por outros sujeitos, fomentando a discussão sobre aquela experiência em termos de possíveis implicações no caso de sua transposição para a vida real.

Por fim, partindo do pressuposto de que o ciberespaço amplia as fronteiras do real, os defensores das novas tecnologias preconizam seu importante papel na atividade imaginativa, contestando a crítica do "déficit de magia" (Kensky; Aguerre, 2003; Gomes, 2013). Embora os próprios criadores dos jogos eletrônicos admitam que eles se tornaram mais reais graças aos avanços tecnológicos e às possibilidades abertas pela internet, o acréscimo de elementos irreais, somado à proposição de situações desafiadoras e estimulantes em um contexto familiar e emocionalmente seguro, e o constante exercício do faz de conta encorajariam a iniciativa para a resolução de problemas e a abertura para outras possibilidades. O pensamento criador e imaginativo seria, portanto, beneficiado pela prática dos jogos eletrônicos.

Como se pode perceber, não obstante a imperiosa necessidade de mais estudos a respeito dos efeitos das tecnologias no comportamento humano, dado que muitos de seus achados devem ser traduzidos como uma advertência aos riscos gerados pela exposição massiva às novas mídias, elas desempenham um importante papel na configuração da subjetividade contemporânea e, por conseguinte, na forma de brincar atual. Como respondem eficazmente à solidão e ao sedentarismo infantil e estão em sintonia com alguns dos valores centrais da nossa época - sucesso e rapidez, por exemplo -, as tecnologias tendem a se impor, no contexto da cultura lúdica. Sua hegemonia pode, inclusive, prejudicar a preservação da cultura lúdica tradicional. Porém, acreditamos que isso pode ocorrer, não por causa dos novos meios lúdicos em si mesmos, mas, sim, pela eventual impossibilidade de as crianças brincarem e 
interagirem umas com as outras e com as outras gerações. Seja como for, o que não se pode é contestar a legitimidade dos novos modos de brincar da era digital.

Mas, diante de tudo o que foi abordado até agora, persiste a dúvida: serão as condições atuais propícias ao brincar e, portanto, à conservação e ao desenvolvimento da cultura lúdica?

\section{Impactos na cultura lúdica: riscos e benefícios}

Reiteramos que o próprio ato de brincar garante a vivência e a propagação da cultura lúdica. Ele requer diferentes formas de interatividade, o que significa "ação entre"; ou seja, é preciso agir (de fato e simbolicamente, em pensamento, o que quer dizer operar) e trocar (consigo mesmo e com o outro, real e-por que não? -, virtualmente).

$\mathrm{O}$ ato de brincar também implica liberdade: sendo o etos do brincar a espontaneidade, só se pode denominar brincadeira a ação livre, realizada em uma situação à qual a pessoa adere espontaneamente. Sua motivação é essencialmente intrínseca, pois os logros eventualmente obtidos não são a razão de brincar, mas, sim, o próprio brincar.

Sem isso, as brincadeiras não podem ser praticadas, atualizadas, inventadas, nem difundidas - sejam elas tradicionais, sejam elas digitais.

É importante garantir às futuras gerações o acesso às formas de brincar milenarmente acumuladas, porque brincar, em si mesmo, é um direito, pelo qual a própria vida se afirma, já que, como forma de expressão e compreensão, tornamonos quem somos brincando. Além disso, as brincadeiras são parte do patrimônio cultural, sendo dever dos adultos, responsáveis pelas novas gerações, partilhá-lo, difundindo-o.

Não se trata, contudo, de agir na perspectiva do "resgate" ou da mera preservação do direito de brincar e das próprias brincadeiras, enrijecendo uma manifestação cultural que é, por excelência, dinâmica. Como recorda Sprea (2010), citando o antropólogo Hermano Vianna, resgate é para sequestrados, acidentados, desaparecidos. Se algumas brincadeiras desaparecem ou são substituídas, deve-se questionar sobre quais são as condições atuais para experimentá-las: será que os adultos não estão renunciando ao papel de mediadores dessa cultura? Que tempo e espaço para brincar não só são ofertados como também partilhados com as crianças e jovens de hoje?

Brincadeiras milenares como sapata, bolinha de gude, fita ou passa-anel, por exemplo, correm sério risco de extinção, se as crianças de hoje não tiverem com quem aprendê-las, tampouco onde e com quem brincar. Somente assim, elas poderão transmiti-las, no futuro, para outras crianças. Como quem as conhece são as gerações anteriores, são elas que poderão ensinar tais brincadeiras e, mais do que isso - sem o que esse aprendizado não se realiza -, oferecer efetivas oportunidades para brincar. O problema deixa de ser, por exemplo, dar ou não dar um tablet como presente de Natal a uma criança, para converter-se em assumirmos ou não o papel de mediadores consequentes da cultura, na qualidade de responsáveis pelas novas gerações. 
Sob essa perspectiva, também a questão da colonização dos jogos eletrônicos adquire outro sentido.

Há de se considerar que todo jogo, eletrônico ou não, tem algum conteúdo, seja ele pedagógico, fantástico, violento ou, simplesmente, relativo aos modos de ser e de viver de determinada época. A ele subjaz uma visão de mundo que também é assimilada quando se joga. Entretanto, ao contrário do que muitos pensam, a assimilação desse conteúdo, junto com a visão de mundo e seus valores implícitos, não é passiva; na verdade, trata-se de uma apropriação ativa por meio da qual quem joga ressignifica reiteradamente aquele objeto lúdico e, por conseguinte, seu conteúdo. Por isso, a ação livre é tão importante para que a brincadeira de fato ocorra. Mas, também por isso, a interação é fundamental: é ela que permitirá os ajustes, as atualizações e as adaptações tanto à realidade quanto aos desejos, renovando seu sentido.

Portanto, se quisermos, efetivamente, assegurar o direito de brincar das crianças e dos jovens de hoje - e também daqueles que hão de sê-lo no futuro -, contribuindo, a um só tempo, para o exercício do direito de brincar e para a transmissão e a constante reinvenção da cultura lúdica, precisamos assumir, de forma consciente e consequente, o papel de partícipes ativos desse processo.

\section{Conclusão}

Ao cabo desta rápida análise, é fácil perceber que há muito a pesquisar sobre o assunto e que muitas das preocupações que cercam a discussão sobre as relações entre o comportamento lúdico infantil na contemporaneidade não são novas, não obstante a recente presença da tecnologia digital na sociedade: a constante ameaça que a atividade lúdica sofre quanto a ser colonizada por interesses extrínsecos e, mais do que isso, espúrios à brincadeira é uma delas; da mesma forma, a problemática da mediação da brincadeira - um papel que as gerações adultas oscilam em assumir, ora de modo demasiadamente intrusivo, ora com lassidão, resultando em omissão no que se refere à transmissão e à recriação da cultura lúdica e, por conseguinte, na participação na aprendizagem social da brincadeira.

Por isso, discutir o papel do adulto diante da criança e da cultura lúdica na era digital é tão importante. Para além de, simplesmente, autorizar ou negar o uso do computador para jogar ou, ainda, limitar o tempo de acesso aos jogos eletrônicos, por exemplo, cabe-lhe ser parceiro das descobertas infantis nesse ambiente virtual, ajudando a criança a elaborar seus novos conhecimentos e experiências. Oferecerlhe oportunidade de interagir com outras crianças também é fundamental: elas, assim, partilham e constroem cultura, mas também se regulam mutuamente em relação às tecnologias digitais. As experiências de uso partilhado do computador exemplificam isso, trazendo como resultados: a promoção do diálogo e a cooperação mútua, o revezamento e a transmissão do conhecimento, mitigando, ainda, o poder de "abdução" que tem a tela quando usada individualmente (Martinez, 2011).

Isso, porém, não é privilégio das situações que envolvem as mídias digitais. A bem da verdade, é o que se espera de todo adulto que ama o mundo o bastante 
para assumir sua responsabilidade sobre ele e pelas novas gerações, tal como Hanna Arendt (2007) já ensinara.

Têm, pois, razão Palfrey e Gasser (2011, p. 16), quando declaram que "as necessidades de limites são sociais, não tecnológicas; as melhores soluções não são proibir o uso da tecnologia, mas ensinar como usar melhor as ferramentas tecnológicas".

\section{Referências bibliográficas}

ALVES, L. Game over: jogos eletrônicos e violência. São Paulo: Futura, 2005.

ARENDT, H. Entre o passado e o futuro. 6. ed. São Paulo: Perspectiva, 2007.

CARNEIRO, M. A. B.; DODGE, J. A descoberta do brincar. São Paulo:

Melhoramentos; Boa Companhia, 2007.

CARR, N. The shallows: what the internet is doing to our brains. New York: W. W. Norton, 2010.

COLONNESE, F. As interferências da mídia no processo de identificação do adolescente. In: LEVISKY, D. (Org.). Adolescência pelos caminhos da violência. São Paulo: Casa do Psicólogo, 1998. p. 161-172.

COSENZA, R. M. Entrevista: para entender os nativos digitais. Pátio Educação Infantil, Porto Alegre, v. 9, n. 28, p. 16-18, jul./set. 2011.

FOLQUE, M. A. Educação infantil, tecnologia e cultura. Pátio Educação Infantil, Porto Alegre, v. 9, n. 28, p. 8-11, jul./set. 2011.

GOMES, S. S. Brincar em tempos digitais. Presença Pedagógica, Belo Horizonte, v. 19, n. 113, p. 44-51, set./out. 2013.

GULARTE, D. Jogos eletrônicos: 50 anos de interação e diversão. Teresópolis: Novas Ideias, 2010.

KENSKI, R.; AGUERRE, G. Armas de diversão em massa. Superinteressante, São Paulo, 31 maio 2003. Disponível em: < https://super.abril.com.br/historia/ armas-de-diversao-em-massa/> .

LEVISKY, D. A mídia: interferências no aparelho psíquico. In: LEVISKY, D. (Org.). Adolescência pelos caminhos da violência. São Paulo: Casa do Psicólogo, 1998. p. $145-160$.

MARTINEZ, J. P. O computador na sala de aula. Pátio Educação Infantil, Porto Alegre, v. 9, n. 28, p. 13-15, jul./set. 2011.

McGONIGAL, J. A realidade em jogo: por que os games nos tornam melhores e como eles podem mudar o mundo. Rio de Janeiro: Best Seller, 2012. 
PALFREY, J.; GASSER, U. Nascidos na era digital: entendendo a primeira geração de nativos digitais. Porto Alegre: Artmed, 2011.

SANCHO, J. M. De geração Einstein a geração estúpida. Pátio Ensino Médio, Porto Alegre, v. 5, n. 18, p. 6-9, set./nov. 2013.

SINGER, D. G.; SINGER, J. T. Imaginação e jogos na era eletrônica. Porto Alegre: Artmed, 2007.

SPREA, N. Brincantes: um documentário sobre a invenção de brincadeiras na escola. 2. ed. Curitiba: Parabolé Educação e Cultura, 2010.

STRASBURGER, V. Os adolescentes e a mídia: impacto psicológico. Porto Alegre: Artmed, 1999.

TRAMONTINA, S. Os riscos da internet para as crianças. Pátio Educação Infantil, Porto Alegre, v. 9, n. 28, p. 37-39, jul./set. 2011.

VEEN, W.; WRAKKING, B. Educação na era digital. Pátio Educação Infantil, Porto Alegre, v. 9, n. 28, p. 4-7, jul./set. 2011.

WEISS, M. L. L. Internet: questões básicas da aprendizagem do adolescente. Revista Psicopedagogia, São Paulo, v. 19, n. 56, p. 74-78, out. 2001.

Tânia Ramos Fortuna, doutora em Educação, é professora de Psicologia da Educação na Faculdade de Educação da Universidade Federal do Rio Grande do Sul. Coordenadora geral do Programa de Extensão Universitária "Quem quer brincar?". tania.fortuna@terra.com.br

Recebido em 19 de janeiro de 2018.

Aprovado em 25 de abril de 2018. 
